\title{
Recovery time after intra-abdominal transmitter placement for telemetric (neuro) physiological measurement in freely moving common marmosets (Callitrix jacchus)
}

Jaco Bakker ${ }^{1 *}$, Rianne Klomp ${ }^{1}$, Milene WM Rijnbeek ${ }^{2}$, Saskia S Arndt ${ }^{2}$, Ingrid HCHM Philippens ${ }^{3}$ and Jan AM Langermans ${ }^{1}$

\begin{abstract}
Background: Telemetry is very important for monitoring physiological functions in awake and freely moving laboratory animals. Although implantable transmitters reduce stress resulting from daily handling and restraint, the procedure requires invasive surgery, which affects behaviour and wellbeing of animals. This aspect is important in cases in which behaviour is used as one of the read-out parameters for studying the progression of a disease and/or the effects of a treatment over time. In mice, implantation of telemetric devices shows changes in body weight, locomotor and eating behaviour, and grooming and immobility activities. In contrast to mice, no specific research has been reported in larger animals. Therefore, effect on motor activity, health status and bodyweight after surgical placement of intra-abdominal transmitter, electroencephalogram (EEG) electrodes and electromyogram (EMG) electrodes in common marmosets (Callithrix jacchus) were assessed. Two behavioural test systems for locomotor function were used: the Hourglass test to measure the time a monkey needs to return to its normal upright position, and the Tower test to measure jumping behaviour. Additionally, health status and bodyweight were monitored daily from 2 weeks pre surgery until 49 days post surgery.

Results: Compared to baseline values, the surgery or the physical presence of the transmitter caused an increase in time needed to achieve an upright position in the Hourglass test. Recovery to baseline values was observed within 8 days post surgery. For the Tower test, the total number of jumps decreased by $80 \%$ directly after surgery. Fifteen days after surgery, the number of jumps normalised, which paralleled an increase in body weight after a 15-day period of body weight decline. By day 31, body weight had normalised to baseline level.

Conclusions: The data from our study show that the surgery led to decreased motor activity, disturbed health status and loss of body weight in the common marmoset. Full recovery, as assessed by reaching all preoperation values, was reached 31 days after surgery. These data are important to optimise the design of future studies utilising these implantable transmitters.
\end{abstract}

Keywords: Common marmoset, Electrodes, Intra-abdominal transmitter, Locomotor capacity, Recovery period

\footnotetext{
*Correspondence: bakker@bprc.nl

${ }^{1}$ Animal Science Department, Biomedical Primate Research Centre, Lange Kleiweg 161, Rijswijk GJ 2288, The Netherlands

Full list of author information is available at the end of the article
} 


\section{Background}

Telemetry is a useful tool for measuring physiological parameters such as heart rate, core body temperature and locomotor activity in conscious, non-restrained animals [1-3]. The standardised approach leads to smaller variations in the biometric data, resulting in more reliable results, refinement of data collection, reduction in animal use, and ultimately in potentially better treatment of disorders [4].

Telemetry has demonstrated its potential in primates [5-7], including data acquisition of brain signals by means of electroencephalogram (EEG) in conscious, unrestrained marmosets [8-11]. However, surgery as well as the presence of the intra-abdominal transmitter are known to affect the wellbeing of mice for 2 weeks after surgery, leading to a change in locomotor activity due to decreased motivation or physical disturbance, which can potentially decrease the reliability of the obtained experimental results $[12,13]$. No specific research regarding influence of the surgery and the presence of the intraabdominal transmitter and EEG and electromyogram (EMG) electrodes on data collection, behaviour and recovery times has been reported in non-rodents.

Common marmosets (Callithrix jacchus) are regularly used in biomedical research to study a variety of human diseases, including neurodegenerative disorders such as Parkinson's disease [14]. Progression of disease can be monitored by studying, for example, home cage activity, motor function and behaviour. Telemetry is used to collect these data without disturbing the animals. In order to obtain reliable data, it is essential that the effects of implantation of the devices in these animals are thoroughly known and minimised before the monitoring starts.

The objectives of our study were to determine the effects of surgical placement of an intra-abdominal transmitter and EEG and EMG electrodes on locomotor activity, health status and bodyweight in common marmosets (Callithrix jacchus).

\section{Results}

Five healthy animals were implanted with a transmitter and electrodes and all provided high quality data (EEG, EMG, core body temperature and locomotor activity) over a period of 49 days. In addition, there were no movement artefacts present on the signal. Visual monitoring of animal movements and behaviours showed that the animals did not appear to be affected by the physical presence of the transmitter and electrode leads. There were no cases of infection subsequent to the implantation procedure.

\section{Evaluation of health status and body weight}

The levels of general appearance showed stable baseline measurements in all animals (score 0), but changed in three out of five marmosets after surgery. These animals displayed stupor during the first 3 days after surgery (score 2). None of the marmosets showed abnormal level of consciousness after 4 days and onwards. A drop in locomotor activity was observed in the first week after surgery (score 1 ), though this was not significantly different $(P>0.05)$ from the baseline behaviour (score 0$)$. Position in the cage and animal behaviour indicated considerable divergence in the pre- as well as in the postoperative period, and no effects induced by the surgical implantation were detected.

Faeces consisted of firm droppings (score 0) during baseline measures until amoxicillin was administered (day -1). Thereafter all animals excreted liquid faeces for 8 days (score 3 ).

Presurgery body weights were relatively constant, as the slope of the regression line of all tested marmosets did not deviate significantly from 0 (Figure 1$)(P=0.957)$. Days 3 to 14 showed a significant decrease in bodyweight estimated at $0.992 \mathrm{~g} /$ day with a $95 \%$ confidence interval $(\mathrm{CI})$ of -1.782 to $-0.199(P=0.0154)$. From day 15 until the end of the study, an ascending trend in the graphs showed a significant increase in body weight estimated at $0.675 \mathrm{~g} /$ day with a $95 \% \mathrm{CI}$ of 0.539 to 0.810 $(P=5.32 \times 10-14)$. The baseline body weight was reached after 31 days post-surgery.

\section{Testing locomotor capacity}

After surgery, all animals displayed a similar increase (not significant) in righting time in the Hourglass test compared to baseline values for a timeframe of 7 days (Table 1). Starting from day 8, the righting times decreased, and mean values (from day 8 to end of the study) even declined below baseline values. Animal \#5 showed deviant turning results, even during presurgery sessions. In some trials, the monkey did not turn at all. In previous studies this inability to turn during baseline data collection was never observed. Based on the high standard deviation of this monkey during the baseline sessions, this marmoset was not included for statistical analyses.

The Tower test data (Table 1 ) revealed that the total number of level changes in a 10-minute test period were significantly reduced, with 19.16 level changes directly after surgery (days 3 to 7$)$. Significant reductions $(P<0.05)$ relative to baseline values were also observed between days 8 to 14 , days 22 to 27 and days 37 to 48 . All animals reached the top level at least once in each test session, both pre as well as post surgery.

Data derived from an independent study ( $\mathrm{n}=10$ normal non-treated animals) showed a decrease of 33\% in turning time between weeks 0 and 3 of their testing.

Baseline values of the Hourglass test after habituation (last-measured preoperative values) were compared to 

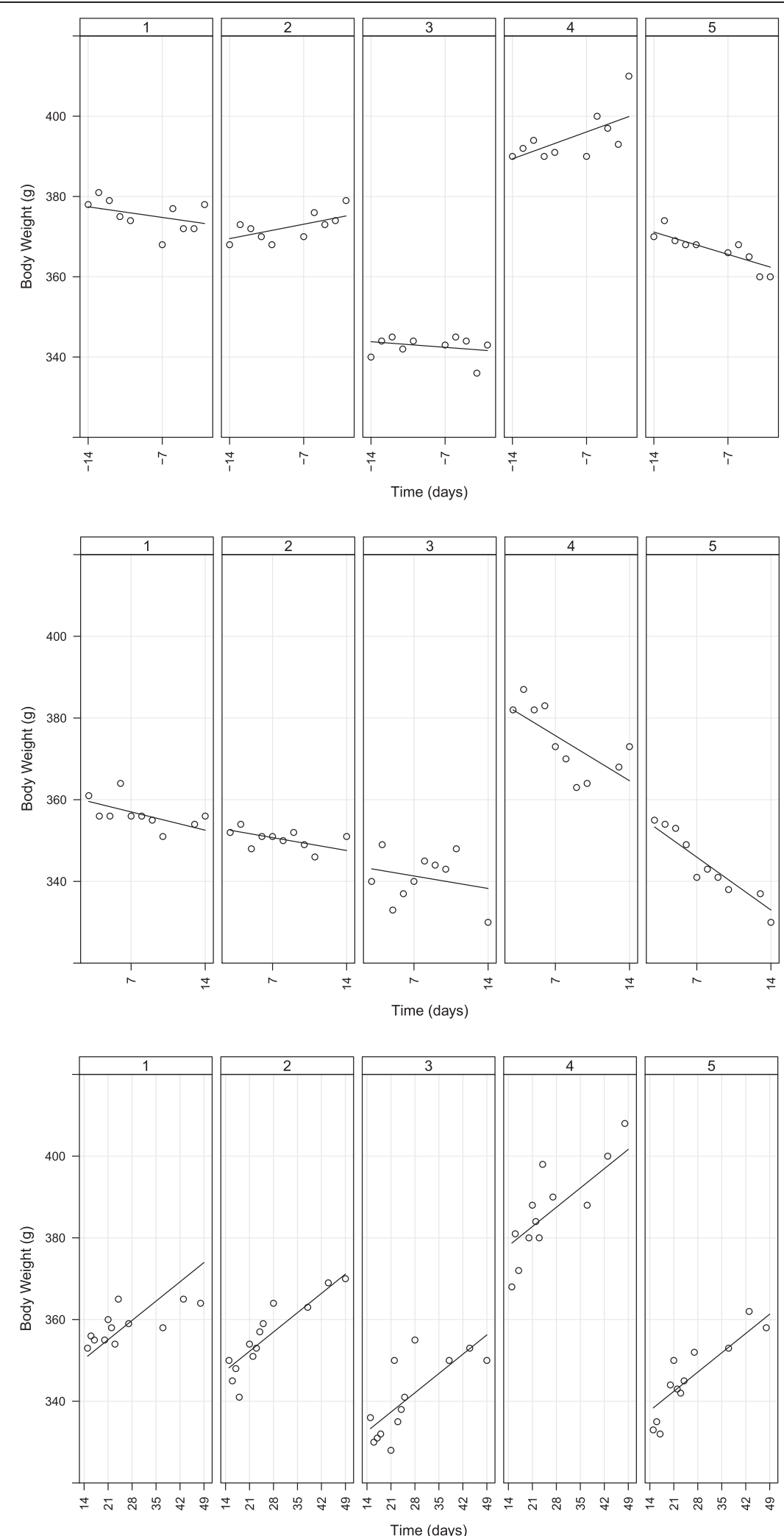

Figure 1 Regression lines of bodyweight per marmoset per predefined period. (Top: days -14 to 0; Middle: days 0 to 14; Bottom: days 14 to 49 ); 1 to 5 correspond to animals \#1 to 5 . 


\begin{tabular}{|c|c|c|c|c|c|c|c|}
\hline \multirow{2}{*}{$\begin{array}{l}\text { Parameter } \\
\text { (Mean } \pm \text { Sem) }\end{array}$} & \multicolumn{7}{|l|}{ Days } \\
\hline & $-7--3$ & $3-7$ & $8-14$ & $15-21$ & $22-27$ & $28-36$ & $37-48$ \\
\hline Tower: & 23.76 & 4.60 & 7.60 & 17.92 & 15.55 & NT & 19.47 \\
\hline Level changes (\#) & \pm 2.05 & \pm 0.62 & \pm 1.30 & \pm 2.51 & \pm 0.88 & & \pm 0.24 \\
\hline Hourglass: & 2.40 & 3.89 & 0.96 & 0.76 & 1.52 & 0.96 & 0.80 \\
\hline Turning time (s) & \pm 1.00 & \pm 2.17 & \pm 0.29 & \pm 0.27 & \pm 0.36 & \pm 0.25 & \pm 0.27 \\
\hline
\end{tabular}

The Tower test data shows a reduction in the total number of level changes after surgery.

The Hourglass data shows an increase in righting time compared to baseline values 1 week after surgery (days 3-7); thereafter righting time was normalised/decreased.

NT: not tested.

the post-peak measures in order to assess whether a learning effect existed. The post-peak measures, excluding days 3-7 post surgery, were all lower than preoperative measures, from which suggest that a habituation effect was present. Data derived from the independent study showed the same habituation effect.

We compared the data collected at days 3 to 7 with baseline data derived from the independent study, which were also in week 3 of their habituation period. These control animals showed a turning time of $1.04 \pm 0.77 \mathrm{~s}$, while the operated animals showed a turning time of $3.89 \pm 2.17 \mathrm{~s}$.

\section{Pathology}

At gross pathology, a visual inspection of the abdominal organs determined no sign of trauma or inflammation in four marmosets (animals \#1 to 4 ) at day 142. The transmitter was fixated to the ventral abdominal wall, electrode wires were still intact, fixed at the right location and no adjacent tissue was damaged. All five brains showed two macroscopic indentations caused by the screws. However, the dura was still intact. During necropsy of animal \#5 (the marmoset that showed deviant turning results in the hourglass, even during presurgery sessions), severe focal haemorrhagic necrosis of the ceaco-colonal junction was discovered in the dorsal abdomen.

\section{Discussion}

Telemetry is very important for monitoring physiological functions in awake and freely moving laboratory animals $[3,15,16]$. In contrast to mice, no specific research regarding influence of the surgery as well as the presence of the intra-abdominal transmitter and EMG and EEG electrodes on body weight, health status and locomotor activity have been reported in larger laboratory animals. The data from our study show that the surgery led to decreased motor activity, disturbed health status and loss of body weight in the common marmoset. Full recovery, as assessed by reaching all preoperative values, was reached 31 days after surgery. These data are important to optimise the design of future studies utilising these implantable transmitters.

Comparison of the data collected at days 3 to 7 with baseline data derived from an independent study resulted in the assumption that the surgery procedure for the insertion of the intra-abdominal transmitter was the cause of the peak in righting time in the Hourglass test 3 to 7 days post surgery, since for all monkeys this was the only change introduced in this period.

Although implantable transmitters reduce stress resulting from daily handling and restraint, the procedure requires invasive surgery, which affects behaviour and wellbeing of animals [12]. This aspect is of crucial importance in cases in which behaviour is used as one of the read-out parameters for studying the progression of a disease and/or the effects of a treatment over time. In rodents, implantation of telemetric devices resulted in body weight decreased as well as climbing, locomotor and eating behaviour, whereas grooming and immobility activities increased, and full recovery was reached after 2 weeks [12]. Like in rodents, marmosets showed a decrease in bodyweight and disturbance in mobility as demonstrated by their jumping behaviour. However, full recovery took significantly longer, that is, more than 4 weeks. When designing studies in marmosets, this longer recovery period has to be taken into account.

In our study, decrease in body weight was attributed to loss of appetite, to protein catabolism, which follows surgical operations [17], and to diarrhoea. However, in healthy people with antibiotic-associated diarrhoea, diarrhoea caused a loss of water in the persons' stools, but as they continued to eat their normal diet and kept fluids up, they stayed roughly the same weight [18]. The gastrointestinal disturbance that was observed in the marmosets started already 1 day before surgery and cannot be directly attributed to surgery. Most likely, oral administration of amoxicillin caused ecological disturbances in the normal intestinal microflora, resulting in diarrhoea [19-22].

At necropsy, no pathological disturbances were observed due to the intra-abdominal implantation and subcutaneous tunnelled electrode leads. One animal had an old haemorrhagic area of the cerosa of the ceco-colonal junction. Because the lesion was located in the dorsal abdomen, while the transmitter was fixated to the ventral abdominal wall, this lesion could not be directly linked to the abdominal transmitter. This lesion is of unknown etiology. This animal also showed atypical turning results in the hourglass test pre surgery.

Critics of the transmitter implantation correctly inquire as to the effects of the weight and volume of the implanted transmitter on animal behaviour and stress and on physiological functions [16]. However, if an appropriate recovery period is taken into account, this surgery does not 
interfere with research results, and the health status of marmosets does not appear to be seriously impaired by the insertion of an intra-abdominal transmitter. The difference between the recovery of rodents and marmosets demonstrate that the optimal recovery time has to be assessed for each species separately. In small animal practices, the most common neurological conditions encountered are seizures [23]. To better understand the aetiology and to improve seizure management, telemetry is very helpful as it prevents stress and immobilisation of the animal, disturbing its behaviour and the EEG, especially in epilepsy, neurotoxicology and pharmacology studies [24-26]. Our data show that that postoperative effects must be fully assessed and all physiological and behavioural functions must have been normalised to be able to obtain meaningful data. With a sufficient experimental setup, in which the recovery time is taken into account, this methodology using telemetric data acquisition is of high importance in longitudinal studies towards neurological disorders, such as Parkinson's disease, Alzheimer's disease, sleep disorders and epilepsy.

\section{Conclusions}

Marmosets tolerate the implantation of the transmitter without obvious problems, and all animals were judged to be fully recovered 31 days after surgery. This waiting period should be taken into account in marmosets after transmitter implantation.

\section{Methods}

\section{Animals, housing and care}

Five adult female common marmosets (Callithrix jacchus), aged $3.8 \pm 0.3$ years and weighing $366.6 \pm 9.4 \mathrm{~g}$ housed at the Biomedical Primate Research Centre (BPRC, Rijswijk, The Netherlands) were used. Each animal was given a complete physical, haematological and biochemical examination before start of the study. All animals displayed all values within the normal range. The monkeys remained under veterinary supervision during the entire study. Animals were housed as described earlier [27]. Food was removed $16 \mathrm{~h}$ prior to surgery but water intake was never restricted.

\section{Ethics}

This study protocol was reviewed and approved by the institute's ethics committee (DierenExperimentenCommissie (DEC)) before the start of experiment (approval number DEC698). The procedures performed in this study were in accordance with the Dutch law on animal experimentation, with the regulations for animal handling as described in the EU Directive 63/2010, and with the Weatherall report (2006).

\section{Experimental design}

A study with each animal acting as its own control was designed (Table 2). Measurements taken during the period prior to surgery (days -14 to 0 ) were adopted as baseline values and were subsequently compared to various periods post surgery. The animals were taken from their home cage to an adjacent quiet, temperaturecontrolled room $\left(24^{\circ} \mathrm{C}\right)$ for measurements of body weight and locomotor capacity testing. A camera for video analysis was installed in this room.

From an independent study ( $\mathrm{n}=10$ normal nontreated animals), data were derived from the Tower and Hourglass tests to determine the habituation effect to these two tests. These 10 animals were tested for 3 successive weeks. Housing and care were similar as described above.

\section{Surgery}

One day prior to surgery until 5 days post surgery, $12.5 \mathrm{mg} / \mathrm{kg}$ amoxicillin (Synulox ${ }^{\oplus}$, Pfizer Animal Health B.V., Capelle a/d IJssel, The Netherlands), was administered orally (PO) twice a day. As analgaesia, $1 \mathrm{~h}$ prior to surgery, $0.20 \mathrm{mg} / \mathrm{kg}$ meloxicam (Metacam ${ }^{\circledR}$, Boehringer Inhelheim, Alkmaar, The Netherlands) was administered PO together with $0.02 \mathrm{mg} / \mathrm{kg}$ buprenorphine (Buprecare ${ }^{\oplus}$, AST farma B.V., Oudewater, The Netherlands) intramuscularly (IM). After surgery, animals received meloxicam $(0.10 \mathrm{mg} / \mathrm{kg} \mathrm{PO})$ once daily in combination with buprenorphine $(0.02 \mathrm{mg} / \mathrm{kg} \mathrm{IM})$ twice a day for 2 days.

Anaesthesia was achieved by means of $16 \mathrm{mg} / \mathrm{kg}$ alphaxalone (Alfaxan ${ }^{\oplus}$, Vétoquinol B.V., 's-Hertogenbosch, The Netherlands) IM. Subsequently, the head and abdomen were shaved and prepared with Hibiscrub and Betadine. The marmosets were placed on a heated blanket in order to stabilise body temperature and were breathing room air spontaneously throughout the surgery.

A 1-cm skin incision was made in a transversal direction between the scapulae. A sterile bandage was used to cover this incision when the marmoset was placed in dorsal recumbency in order to make a $3-\mathrm{cm}$ incision in

Table 2 Experimental design

\begin{tabular}{lllll}
\hline Technique & Time (days) & & & \\
\hline & $-14-0$ & 0 & $1-2$ & $3-49$ \\
Surgery & & $x$ & & \\
Scoring of behaviour & $x$ & $x$ & $x$ & $x$ \\
Body weight & $x$ & $x$ & $x$ & $x$ \\
Hourglass test & $x$ & & & $x$ \\
Tower test & $x$ & & & $x$ \\
EEG check & & $x$ & & $x$ \\
\hline
\end{tabular}

Days -14 to 0: Period prior to surgery; baseline values of behaviour and body weight were obtained. Day 0: surgery. Days 1 to 49: After surgery; possible alterations on behaviour and body weight were measured. 
Table 3 Clinical scoring system to assess health status

\begin{tabular}{|c|c|c|}
\hline Parameter & Evaluation scale (including but not limited to these clinical signs) & Parameter \\
\hline \multirow[t]{5}{*}{ General appearance } & Normal, alert & 0 \\
\hline & Abnormal or hunched posture, dull appearance to eyes, dehydration, notable weight loss & 1 \\
\hline & $\begin{array}{l}\text { Stupor: A state of impaired consciousness characterised by a marked diminution in } \\
\text { the capacity to react to environmental stimuli }\end{array}$ & 2 \\
\hline & Sopor: a deep, lethargic or unnatural sleep & 3 \\
\hline & $\begin{array}{l}\text { Coma: a state of extreme unresponsiveness, in which an individual exhibits no } \\
\text { voluntary movement or behaviour. Even painful stimuli (actions which, when } \\
\text { performed on a healthy individual, result in reactions) are unable to affect any } \\
\text { response, and normal reflexes may be lost }\end{array}$ & 4 \\
\hline \multirow[t]{3}{*}{ Skin and fur } & Normal & 0 \\
\hline & Ruffled fur, unkept appearance & 1 \\
\hline & Rash, pallor, redness, icterus, petechiae, ccchymoses, wound, abscess, ulcer & 2 \\
\hline \multirow[t]{3}{*}{ Respiration } & Normal & 0 \\
\hline & Increased $(>60)$ or decreased respiration rate per minute $(<50 / \mathrm{min})$, cough, sneezing & 1 \\
\hline & Dyspnoea, open mouth breathing, cyanosis & 2 \\
\hline \multirow[t]{4}{*}{ Faeces and urine } & Normal consistency and volume & 0 \\
\hline & Decreased faeces, fry, wet and pasty, discoloration decreased urine, discoloration & 1 \\
\hline & Faeces absent & 2 \\
\hline & Liquid faeces (if debilitating), urine absent, blood in faeces or urine & 3 \\
\hline \multirow[t]{4}{*}{ Food intake } & Normal & 0 \\
\hline & Decreased (eating less than half normal food intake) & 1 \\
\hline & Eating biscuits but no fruit or pellets & 2 \\
\hline & Severely decreased (not eating biscuits) & 3 \\
\hline \multirow[t]{5}{*}{ Locomotor activity } & Normal & 0 \\
\hline & $\begin{array}{l}\text { Hyperactivity (circling, increased aggression); Hypoactivity (hunched, inactive on } \\
\text { camera, active with people in room) }\end{array}$ & 1 \\
\hline & Ataxia, neurological signs (tremors, head tilt), loss of interest in treats & 2 \\
\hline & $\begin{array}{l}\text { Reluctant to move, uses cage for support, difficulty getting to food or water } \\
\text { (decreased response to human presence), seizures }\end{array}$ & 3 \\
\hline & Down with no or minimal response to human approach, coma & 4 \\
\hline \multirow[t]{2}{*}{ Position in the cage ${ }^{a}$} & Upper part & \\
\hline & Bottom part & \\
\hline \multirow[t]{7}{*}{ Social behaviour ${ }^{\mathrm{a}}$} & Scent-marking & \\
\hline & Twisting & \\
\hline & Slit stare & \\
\hline & Grooming & \\
\hline & Sitting and resting & \\
\hline & Walking, running, climbing and jumping gaps between objects & \\
\hline & $\begin{array}{l}\text { 'Bouncing gait': running with an exaggerated bouncing movement and frequently } \\
\text { included bouncing off objects }\end{array}$ & \\
\hline
\end{tabular}

${ }^{\mathrm{a} S c o r e d}$ in number of occurrences per minute.

the abdominal skin (below the umbilicus) along the midline. Subsequently, the skin was separated from the abdominal muscles. The abdomen was opened, and the sterile transmitter (TL11M2-F40-EET, PhysioTel ${ }^{\oplus}$, Data Sciences (DSI), St. Paul, MN, USA) was placed inside the abdominal cavity. The electrode wires originating from the transmitter were tunnelled through the abdominal wall (on the right side of the abdominal incision) by means of an over-the-needle catheter. The transmitter had a ridge containing four holes on the upper surface 
which were used to attach to the abdominal wall during wound closure with absorbable sutures (Vicryl Plus suture 4-0, Ethicon/Johnson \& Johnson). The electrode wires, which protruded through the abdominal wall, were tunnelled subcutaneously to the skin incision between the scapulae by means of an over-the-needle catheter. After tunnelling, the abdominal skin incision was closed with single-knot sutures (Vicryl Plus suture 4-0) and covered with wound spray. Subsequently, the skull was exposed by means of an anterior to posterior skin incision across the top of the head between the ears. Two out of four wires from the skin incision between the scapulae to the skin incision in the head were tunnelled. The periost of the skull was scraped back and thoroughly scratched using a scalpel blade no. 10. A cotton swab soaked in $35 \%$ hydrogen peroxide was used to degrease the surface of the skull. Two small holes were drilled, both at $3 \mathrm{~mm}$ lateral (right) to the sagittal suture and $2 \mathrm{~mm}$ and $9 \mathrm{~mm}$ anterior of the bregma, respectively, using a dental drill. The electrode wires were pushed through these holes and fixed by stainless steel screws. The screws reached the dura and did not penetrate the cortex. The heads of the screws were completely covered with cement (Antibiotic Simplex ${ }^{\odot}$ P with Tobramycin (0.5 dose CE) bone cement, Stryker Corporation, Meyzieu, France), which also continued over the surrounding skull. Subsequently, the skin incision was closed using Vicryl Plus suture 4-0. The remaining two electrode wires protruding from the incision in the scapula area were tunnelled subcutaneously by means of an over-the-needle catheter and fixed with a single stitch to either the chin muscle ( $m$. trigonum submandibularis) or to the neck muscle (m. trapezius) for EMG data recording. Stitching required a small incision above the respective muscles, subsequently closed with single-knot sutures (Vicryl Plus suture 4-0) and covered with wound spray. The animals recovered in their home cage on an open non-heated blanket.

\section{Assessment of health status and body weight}

The health status of the marmosets was evaluated through daily visual assessment between 15:00 and 16:00. during the entire study. The scoring system included numeric values for general appearance, respiration, faeces and urine production, food intake, locomotor activity, and evaluation of skin and fur coat. Position in the cage was also scored. Social behaviours were classified as described by Stevenson and Poole [28] and number of occurrences per minute were scored (Table 3).

The body weight was measured each working day. Marmosets had been trained to voluntarily enter a Perspex cylinder and were taken out of their cage by means of this cylinder. The cylinder with the animal was placed on a weighing scale to assess body weight.

\section{Testing locomotor capacity}

The Hourglass (Figure 2) and Tower tests (Figure 3) were used to measure a decrease in motor function as indicator for both physical discomfort and motivation to move [29]. Physical disturbance caused by the intra-abdominal transmitter can result in an extended righting time [30]. A cylinder measuring $11 \mathrm{~cm} \mathrm{x} 27 \mathrm{~cm}$ was used to turn the animal upside down. One trial period consisted of turning the cylinder $180^{\circ}$, causing the marmoset to be in a headdown position, to the moment the marmoset is once again in an upright position. The time it took for the marmoset to turn back in the upright position was noted with nonautomated video analysis, done by an observer. Intervals between cylinder turn and the marmoset's ability to recover its position (head above legs) was noted (righting time), maximum time noted was $30 \mathrm{~s}$ (also for marmosets which did not turn upright at all). One test comprised 10 $180^{\circ}$ turns of the cylinder.

The Tower test setup consisted of a 230-cm high cabinet with a transparent plexiglas front, in which five horizontally situated crossbars with varying distances between 10, 19, 45, 70 and $50 \mathrm{~cm}$, respectively, were present. At the start of a test, a marmoset was located behind a sliding door adjacent to the bottom of the cabinet. After opening of the sliding door, the marmoset enters the cabinet. Simultaneously, an observer sitting in another room in front of a video screen recorded each point of time the marmoset jumped from one level to another over a 10-min period. The scoring results of the Tower test showed the amount of time the marmoset was present on each level and the total number of jumps in this 10-min period.

\section{Transmitter data acquisition}

Post surgery, a weekly check was performed to ensure that the abdominal transmitter was functioning properly. The transmitter could be switched on and off by a magnetic switch passing a magnet along the respective monkey at a distance of about 1 to $2 \mathrm{~cm}$ from its surface. Signals from the telemetric devices were transmitted to a receiver (RPC-1, Data Sciences International, St. Paul, MN, USA) placed at a distance of about $20 \mathrm{~cm}$ from the transmitter. In order to assemble signals, the Perspex cylinder containing one marmoset was placed on top of the receiver. Signals collected by the receiver were consolidated and stored by way of a consolidation matrix (Data Exchange Matrix CH20, Data Sciences International, St. Paul, MN, USA) attached to a computer equipped with Data Science ART 4.1 software for signal processing.

\section{Pathology}

Necropsy was performed on all marmosets 142 days post surgery. The abdominal cavity was opened and the 


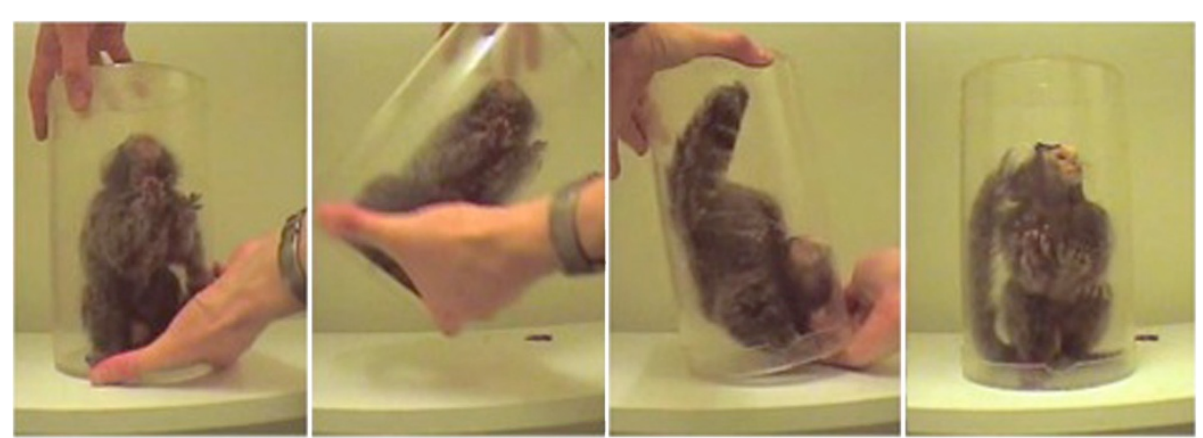

Figure 2 Image of Hourglass. A cylinder measuring $11 \mathrm{~cm} \times 27 \mathrm{~cm}$ was used to turn the animal upside down in the Hourglass setup. One trial period consisted of turning the cylinder $180^{\circ}$, causing the marmoset to be in a head-down position, to the moment the marmoset is once again in an upright position. Intervals between cylinder turn and the marmoset's ability to recover its position (head above legs) was noted (righting time) with non-automated video analysis, done by an observer. Maximum time noted was $30 \mathrm{~s}$ (also for marmosets which did not turn upright at all). One test comprised $10180^{\circ}$ turns of the cylinder.

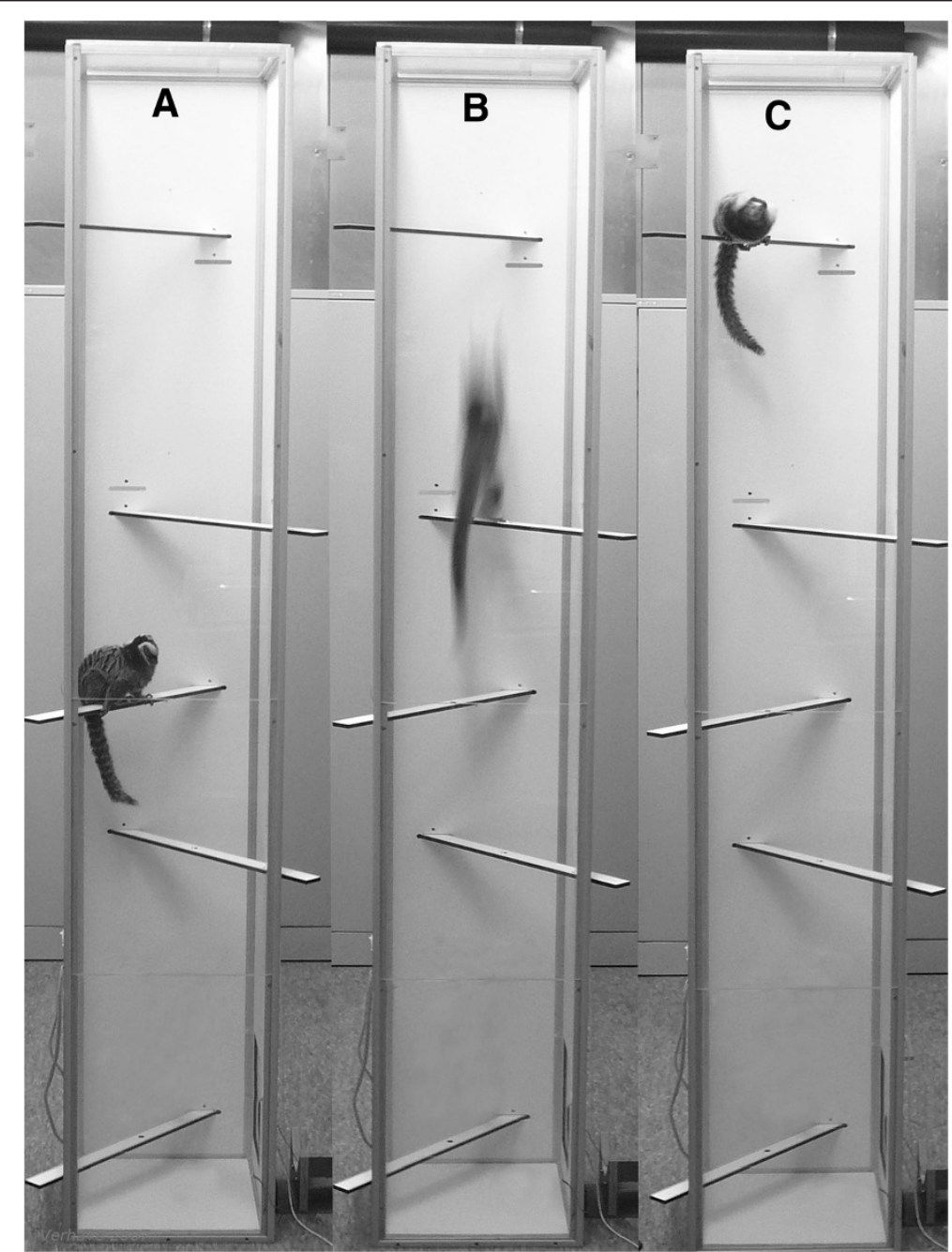

Figure 3 Image of Tower. The Tower test setup consisted of a 230-cm high cabinet with a transparent Plexiglas front, in which five horizontally situated crossbars with varying distances between 10,19, 45, 70 and $50 \mathrm{~cm}$, respectively. At the start of a test, a marmoset was located behind a sliding door adjacent to the bottom of the cabinet. After opening of the sliding door, the marmoset enters the cabinet. Simultaneously, an observer sitting in another room in front of a video screen recorded each point of time the marmoset jumped from one level to another over a 10-min period. The figure shows a marmoset at level 3 (A) and jumping (B) to level 5 (C). 
abdominal organs were inspected for possible trauma or inflammation caused by the transmitter. Electrode wires were followed to the skull to determine whether they were still in place and not causing damage to the adjacent tissue. The skull was opened carefully to observe possible indentation in the brain caused by the two screws in the skull.

\section{Statistical analysis}

The experimental design of this study is a 'within-design study', that is, each tested animal acted as its own control. Measurements taken in the period prior to surgery were adopted as baseline values and subsequently compared to various periods post surgery. The postsurgery period was divided in two parts: immediately after surgery (days 3 to 14 ) and recovery (days 15 to 48 ).

Data were collected into Excel spread sheets (Microsoft Corporation, Redmond, VA, USA) and averaged to obtain mean values for baseline as well as both postsurgery periods. These averages were transferred to the statistical processing program $\mathrm{R}$ [31].

Baseline and postsurgery weight averages were initially compared using paired $\mathrm{t}$-tests (that is, the difference in average body weights was calculated and subsequently tested against the null hypothesis that this difference is 0 ). Postsurgery body weight was corrected for transmitter weight $(7.0 \mathrm{~g})$. Changes in body weight in the three time brackets described above were further analysed using linear mixed models. The mixed models provide estimates for change in body weight per day, complemented with 95\% CIs, while adjusting for random effects (due to random selection of animals). Mixed effect models with different random effects (random intercept and/or random slope) were defined and fitted. The model with the best fit (as represented by the lowest Akaike Information Criterion (AIC)) was subsequently used to calculate the weight change per day. The level of probability for accepting statistical significance was set at $P<0.05$.

In order to standardise the results of the Hourglass test, only eight out of 10 trials conducted of each test session were included (the lowest and the highest scores of each monkey within one session were not taken into account) to analyse the same number of turns for each animal.

\section{Competing interests}

None of the authors has any financial or personal relationships that could inappropriately influence or bias the contents of this paper.

\section{Authors' contributions}

JB designed and coordinated the study, collected and analysed the data, performed the statistical analysis and wrote the final version of the manuscript. JAML and IHCHMP assisted in designing the study; RK and MWMR collected data; RK, SSA, IHCHMP, MWMR and JAML analysed the data; MWMR assisted performing statistical analysis; and SSA, IHCHMP and JAML assisted writing the manuscript. All authors read and approved the final manuscript.
Authors' information

Ingrid HCHM Philippens and Jan AM Langermans are senior authors.

\section{Acknowledgements}

This study was in part supported financially by EUPRIM-NET2, grant agreement no. 262443. The authors would like to thank Marloes Joosen, Peter Pearce and Manon Schaap for useful and helpful comments on this study; Ed Remarque for statistical analysis; Ivanela Kondova for expert pathological examination and advice; Henk van Westbroek for optimising the figures; and Donna Devine and Thea de Koning for editing the manuscript.

\section{Author details}

'Animal Science Department, Biomedical Primate Research Centre, Lange Kleiweg 161, Rijswijk GJ 2288, The Netherlands. ${ }^{2}$ Department of Animals in Science \& Society, Division of Animal Welfare \& Laboratory Animal Science, Faculty of Veterinary Medicine Utrecht University, Utrecht, The Netherlands.

${ }^{3}$ Department of Immunobiology, Biomedical Primate Research Centre, Lange Kleiweg 161, Rijswijk GJ 2288, The Netherlands.

Received: 17 January 2014 Accepted: 16 May 2014

Published: 9 June 2014

\section{References}

1. Gauvin DV, Tilley LP, Smith FW Jr, Baird TJ: Electrocardiogram, hemodynamics, and core body temperatures of the normal freely moving laboratory beagle dog by remote radiotelemetry. J Pharmacol Toxicol Methods 2006, 53:128-139.

2. Kramer K, van Acker SA, Voss HP, Grimbergen JA, van der Vijgh WJ, Bast A: Use of telemetry to record electrocardiogram and heart rate in freely moving mice. J Pharmacol Toxicol Methods 1993, 30:209-215.

3. Lange J, Brockway B, Azar S: Telemetric monitoring of laboratory animals: an advanced technique that has come of age. Lab Anim 1991, 20:28-33.

4. van Acker SA, Kramer K, Voest EE, Grimbergen JA, Zhang J, van der Vijgh WJ, Bast A: Doxorubicin-induced cardiotoxicity monitored by ECG in freely moving mice. A new model to test potential protectors. Cancer Chemother Pharmacol 1996, 38:95-101.

5. Authier S, Haefner P, Fournier S, Troncy E, Moon LB: Combined cardiopulmonary assessments with implantable telemetry device in conscious freely moving cynomolgus monkeys. J Pharmacol Toxicol Methods 2010, 62:6-11.

6. Gauvin DV, Tilley LP, Smith FW Jr, Baird TJ: Electrocardiogram, hemodynamics, and core body temperatures of the normal freely moving cynomolgus monkey by remote radiotelemetry. J Pharmacol Toxicol Methods 2006, 53:140-151.

7. Schnell CR, Wood JM: Measurement of blood pressure and heart rate by telemetry in conscious unrestrained marmosets. Lab Anim 1995, 29:258-261.

8. Crofts HS, Wilson S, Muggleton NG, Nutt DJ, Scott EA, Pearce PC: Investigation of the sleep electrocorticogram of the common marmoset (Callithrix jacchus) using radiotelemetry. Clin Neurophysiol 2001, 112:2265-2273.

9. Pearce PC, Crofts HS, Muggleton NG, Scott EA: Concurrent monitoring of EEG and performance in the common marmoset: a methodological approach. Physiol Behav 1998, 63:591-599.

10. Philippens $\mathbb{H}$, Vanwersch RA: Neurofeedback training on sensorimotor rhythm in marmoset monkeys. Neuroreport 2010, 21:328-332.

11. Verhave PS, Jongsma MJ, Van den Berg RM, Vis JC, Vanwersch RA, Smit AB, Van Someren E, Philippens IH: REM sleep behavior disorder in the marmoset MPTP model of early Parkinson disease. Sleep 2011, 34:1119-1125.

12. Baumans V, Bouwknecht JA, Boere $H$, Kramer $K$, van Lith $H A$, van de Weerd $H A$, van Herck H: Intra-Abdominal Transmitter Implantation in Mice: Effects on Behaviour and Body Weight. Anim Welf 2001, 10:291-302.

13. Mills PA, Huetteman DA, Brockway BP, Zwiers LM, Gelsema AJ, Schwartz RS, Kramer K: A new method for measurement of blood pressure, heart rate, and activity in the mouse by radiotelemetry. J Appl Physiol 2000, 88:1537-1544

14. Philippens $\mathbb{H}$, Wubben JA, Finsen $B, B A$ t H: Oral treatment with the NADPH oxidase antagonist apocynin mitigates clinical and pathological features of parkinsonism in the MPTP marmoset model. J Neuroimmune Pharmacol 2013, 8:715-726. 
15. Kramer K, Kinter L, Brockway BP, Voss HP, Remie R, Van Zutphen BL: The use of radiotelemetry in small laboratory animals: recent advances. Contemp Top Lab Anim Sci 2001, 40:8-16.

16. Kramer K, Kinter LB: Evaluation and applications of radiotelemetry in small laboratory animals. Physiol Genomics 2003, 13:197-205.

17. Post-operative Weight Loss. Br Med J 1955, 1:212-213.

18. Beaugerie L, Carbonnel F, Carrat F, Rached AA, Maslo C, Gendre JP, Rozenbaum W, Cosnes J: Factors of weight loss in patients with HIV and chronic diarrhea. I Acquir Immune Defic Syndr Hum Retrovirol 1998, 19:34-39.

19. Bergogne-Berezin E: Treatment and prevention of antibiotic associated diarrhea. Int J Antimicrob Agents 2000, 16:521-526.

20. Hogenauer C, Hammer HF, Krejs GJ, Reisinger EC: Mechanisms and management of antibiotic-associated diarrhea. Clin Infect Dis 1998, 27:702-710.

21. McFarland LV: Epidemiology, risk factors and treatments for antibioticassociated diarrhea. Dig Dis 1998, 16:292-307.

22. Turck D, Bernet JP, Marx J, Kempf H, Giard P, Walbaum O, Lacombe A Rembert F, Toursel F, Bernasconi P, Gottrand F, McFarland V, Bloch K: Incidence and risk factors of oral antibiotic-associated diarrhea in an outpatient pediatric population. J Pediatr Gastroenterol Nutr 2003, 37:22-26.

23. Munana KR: Update: seizure management in small animal practice. Vet Clin North Am Small Anim Pract 2013, 43:1127-1147.

24. Bastlund JF, Jennum P, Mohapel P, Vogel V, Watson WP: Measurement of cortical and hippocampal epileptiform activity in freely moving rats by means of implantable radiotelemetry. J Neurosci Methods 2004, 138:65-72.

25. de Araujo FM, Zheng A, Sedigh-Sarvestani M, Lumley L, Lichtenstein S, Yourick D: Analyzing large data sets acquired through telemetry from rats exposed to organophosphorous compounds: an EEG study. J Neurosci Methods 2009, 184:176-183.

26. Mumford $H$, Wetherell JR: A simple method for measuring EEG in freely moving guinea pigs. I Neurosci Methods 2001, 107:125-130.

27. Jagessar KL, Jain C: Functional and molecular analysis of Escherichia coli strains lacking multiple DEAD-box helicases. RNA 2010, 16:1386-1392.

28. Stevenson MF, Poole TB: An ethogram of the common marmoset (Calithrix jacchus jacchus): general behavioural repertoire. Anim Behav 1976, 24:428-451.

29. Verhave PS, Vanwersch RA, van Helden HP, Smit AB, Philippens IH: Two new test methods to quantify motor deficits in a marmoset model for Parkinson's disease. Behav Brain Res 2009, 200:214-219.

30. Martens DJ, Whishaw IQ, Miklyaeva El, Pellis SM: Spatio-temporal impairments in limb and body movements during righting in an hemiparkinsonian rat analogue: relevance to axial apraxia in humans. Brain Res 1996, 733:253-262.

31. Team RDC: R: A Language and Environment for Statistical Computing. In Book R: A Language and Environment for Statistical Computing, 3.0.1 (2013-05-16) edition. Vienna, Austria: R Foundation for Statistical Computing. http://www.R-project.org/; 2012. ISBN 3-900051-07-0.

doi:10.1186/2050-3385-2-10

Cite this article as: Bakker et al.: Recovery time after intra-abdominal transmitter placement for telemetric (neuro) physiological measurement in freely moving common marmosets (Callitrix jacchus). Animal Biotelemetry 2014 2:10.

\section{Submit your next manuscript to BioMed Central and take full advantage of:}

- Convenient online submission

- Thorough peer review

- No space constraints or color figure charges

- Immediate publication on acceptance

- Inclusion in PubMed, CAS, Scopus and Google Scholar

- Research which is freely available for redistribution 